\title{
HIGH-STRENGTH ETHYLENE GLYCOL WASTEWATER TREATMENT IN ANAEROBIC POLYVINYL ALCOHOL GEL BEADS BASED BIOFILM REACTOR
}

\author{
YUE J. ${ }^{1}$ \\ QINGLIN X $X^{2}$ \\ WENJIE $Z^{2,3, *}$
}

\author{
${ }^{1}$ Guangxi Key Laboratory of New Energy and Building Energy Saving \\ College of Civil Engineering and Architecture \\ Guilin University of Technology \\ 12, Jiangan Road, Guilin, 541004, P.R. China \\ ${ }^{2}$ Guangxi Key Laboratory of Environmental Pollution Control \\ Theory and Technology \\ Guilin University of Technology, Guilin, 541004, P.R. China \\ ${ }^{3}$ Guangxi Collaborative Innovation Center for Water Pollution Control \\ and Water Safety in Karst Area \\ Guilin University of Technology, Guilin, 541004, P.R. China
}

Received: 21/08/2015

Accepted: 08/12/2015

Available online: $21 / 12 / 2015$ *to whom all correspondence should be addressed: e-mail: 2010053@glut.edu.cn

\section{ABSTRACT}

In this paper, ethylene glycol wastewater (EGW) treatment was studied by using one anaerobic polyvinyl alcohol (PVA) gel beads based biofilm reactor. Enhanced by PVA-gel beads based biofilm, organic loading rate (OLR) about $11 \mathrm{~g} \mathrm{COD} \mathrm{I}^{-1} \mathrm{~d}^{-1}$ was achieved at the end of this study. Black PVA-gel beads with an average settling velocity $322 \mathrm{~m} \mathrm{~h}^{-1}\left(9 \mathrm{~cm} \mathrm{~s}^{-1}\right)$ and $0.24 \mathrm{~g} \mathrm{VSS} \mathrm{g}^{-1}$ PVA gel mainly composed of Methanosarcina spp. were got, while no natural granules were found in this experiment. The COD removal efficiency in this study could reach a high value about $95 \%$. Most COD removal was contributed by the PVA-gel beads based biofilm. It could be concluded that the PVA-gel beads based biofilm reactor is appropriate for EGW treatment.

Keywords: ethylene glycol; wastewater; biofilm; UASB; PVA-gel beads

\section{Introduction}

Ethylene glycol wastewater (EGW) is widely used as raw materials or ingredients in chemical factories (Orecki et al., 2006). In addition, EGW is also drained from airport in winter season, which is characterized with high COD concentrations (Zitomer et al., 2001). Biological aeration process is preferred for EGW treatment owing to the simple startup operation, and good performance (Hassani et al., 2014). However, operational problems, such as sludge bulking, happen due to poor settling velocity, which is still not well understood (Amanatidou et al., 2015).

In recent years, with global concerns over energy shortage and greenhouse gas formation, more efforts toward renewable energy supplies even from wastewater is clearly needed. Anaerobic process, which could run with high loading rate, methane gas generation and less nutrients, is investigated (Diamantis and Aivasidis, 2010; Blika et al., 2009; Vlassis, 2012). Kennedy and Barriault (2005), used lab-scale upflow anaerobic sludge blanket (UASB) reactor to treat EGW, and good removal rate of $93 \%$ was observed.

Successful operation of anaerobic reactor is dependent on the sludge retention time (SRT) (Manser et al., 2015; Vanwonterghem et al., 2015; Dareioti and Kornaros, 2015); the formation of the granules is a 
suggested step. Although anaerobic granules are successfully got in high carbohydrate or sugar containing wastewaters, though, it is still a big challenge to get well granules by using EGW. So, the facility for EGW treatment usually runs in a deduced loading rate.

The Polyvinyl alcohol (PVA) gel beads based biofilm system has been proved effective in treating high strength corn steep liquor (CSL) wastewater (Zhang et al., 2007). Zhang et al., (2009) used PVA-gel beads in a lab-scale anaerobic fluidized-bed (AFB) reactor, and a removal efficiency of $91 \%$ was achieved at an OLR of $27.5 \mathrm{~g} \mathrm{COD} \mathrm{l}^{-1} \mathrm{~d}^{-1}$. In this study, PVA-gel beads with a size of 3-4 mm, which could be produced with low cost, were used as biocarrier in order to get higher loading rate by enhancing SRT. The most significant negative factor that can affect the economics of anaerobic process versus aerobic process is the possible need to add alkalinity and other nutrients, especially for the chemical wastewater, such as EGW. In this experiment, the limit quality for alkalinity and nutrients were determined.

\section{Material and methods}

\subsection{Experimental setup}

In total $1 \mathrm{~L}$ digester sludge and 1.5 I PVA-gel beads with a size of 3-4mm were used. The reactor started with corn steep liquor as synthetic wastewater with COD concentration about $500 \mathrm{mg} \mathrm{l}^{-1}$ (data not shown). After one month, the influent was replaced by EG gradually. The temperature was controlled at $35^{\circ} \mathrm{C}$.

The reactor had an inner diameter of $10 \mathrm{~cm}$ with a working volume of $12.5 \mathrm{I}$ including a reaction section of $7.5 \mathrm{I}$ and a settling zone of $5 \mathrm{I}$. In the settling zone, gas is separated and collected by one gas collector, and solids mainly in the form of digested sludge settle and return back to the sludge layer. After separating the solid and gas from the liquid, the treated water comes out from the reactor. The reactor was made of acrylic resin and was equipped with a water jacket for temperature control and was maintained at about $35^{\circ} \mathrm{C}$. Sampling ports were located at heights of 3, 17, 20, 25 and $32 \mathrm{~cm}$ above the reactor bottom.

\subsection{Analytical techniques}

COD, SS, VSS, VFAs, alkalinity: Filtered COD $(0.45 \mu \mathrm{m})$ was measured by the closed reflux colorimetric method (APHA, 1995). SS and volatile suspended solids (VSS) in effluent and sludge samples were measured in accordance with Standard Methods (APHA, 1995). Alkalinity levels in effluent samples were determined by titration (APHA, 1995). VFAs were quantified by using a CTO-10AS liquid chromatograph (Shimadzu, Japan).

Gas collection and analysis: Gas was collected through a gas-liquid-solid separator and the volume was measured using an inverted measuring cylinder containing tap water with the $\mathrm{pH}$ lowered to 3 using $1 \mathrm{~N}$ $\mathrm{H}_{2} \mathrm{SO}_{4}$. Gas analyses were performed using a GC-14B gas chromatograph (Shimadzu, Japan) with a Porapak $\mathrm{Q}(80 / 100$ mesh, $4 \mathrm{~m})$ column and a thermal conductivity detector using argon as the carrier gas. For each measurement, $0.1 \mathrm{~mL}$ of gas was taken with a gas-tight syringe and injected into the gas chromatograph.

PVA-gel characteristics: The settling velocity of PVA-gel beads/granules was measured by the method which descried earlier by Zhang et al., (2011). The amount of sludge (biomass or solids) attached to PVA granules (g VSS/g PVA gel) was determined by the wet weight difference from an average of 30 pairs of new (unused) and granulated PVA-gel beads.

Scanning electron microscopy (SEM): Samples were first washed in a $0.1 \mathrm{M}$ phosphate buffer solution (pH 7.4) for $5 \mathrm{~min}$. Then samples were hardened for $90 \mathrm{~min}$ in a $2.5 \%$ glutaraldehyde solution prepared with the buffer solution. Next, samples were washed in the buffer solution three times for 10 min each and then fixed for $90 \mathrm{~min}$ in a $1.0 \% \mathrm{OsO}_{4}$ solution prepared with the buffer solution. After washing samples three times for 10 min each in the buffer solution, they were dewatered for 10 min each in serially graded solutions of ethanol at concentrations of $10,30,50,70,90$, and $95 \%$. SEM observations were conducted using a scanning electron microscope (JEOL, JSM-5310LV, Japan).

Fluorescence in situ hybridization (FISH). PVA-gel beads were shaken briskly by hand in a tube and the liquid was then wasted. Fixation and hybridization of prepared support slices and biomass collected from 
the support medium were carried out according to the method of Amann. To detect archaeal cells, probe EUB338 (5'-end labeled with Cy5 (Amersham Bioscience, Piscataway, NJ, USA)) and probe ARC 915 (5'end labeled with Cy5 (Amersham Bioscience)) were used. An order-specific probe MG1200 (5'-end labeled with FITC (Amersham Bioscience)) was used for the detection of hydrogenotrophic methanogens in the order Methanomicrobiales, including the genus Methanoculleus. A confocal laser scanning microscope FV300 (Olympus, Tokyo) was used for microscopic observation.

\subsection{Substrate}

EG diluted by tap water was prepared at an appropriate concentration. The COD:N:P is 100:6:26 referred to the CSL (Zhang et al., 2009). The urine was used as $\mathrm{N}$ resource; sodium bihydrogen phosphate was used as $\mathrm{P}$ source. Trace nutrients such as $\mathrm{Fe}, \mathrm{Zn}, \mathrm{Cu}, \mathrm{Ni}, \mathrm{Co}, \mathrm{Ca}, \mathrm{K}$, etc were prepared with a proportion in advance and were added according to the influent volume (Zhang et al., 2011).

\subsection{Reactor operation}

The reactor was started with an OLR $1.0 \mathrm{~kg} \mathrm{COD} \mathrm{m}^{-3} \mathrm{~d}^{-1}$ and a HRT $14.4 \mathrm{~h}$ by using CSL as influent (Table 1). After 22 days of cultivation, the influent was gradually replaced by synthetic EGW in 13 days. The HRT was still maintained at $14.4 \mathrm{~h}$. The influent COD level was then increased stepwise to about 3,500 mg I-1 (the designed concentration of the actual wastewater) allowing for stabilization of sludge levels and performance indicators.

In order to test the hydrodynamic effect on the reactor, during phase 6 , the HRT was reduced to $8 \mathrm{~h}$ with an OLR about $10 \mathrm{~kg} \mathrm{COD} \mathrm{m}^{-3} \mathrm{~d}^{-1}$. The most significant negative factor that can affect the economics of anaerobic versus aerobic treatment is the possible need to add alkalinity. Alkalinity concentrations of 2000 to $3000 \mathrm{mg} \mathrm{l}^{-1}$ as $\mathrm{CaCO} 3$ may be needed in anaerobic processes to maintain an acceptable pH with the high gas phase $\mathrm{CO} 2$ concentration. In the following 55 days (phases 7 to 11), the added trace nutrients and $\mathrm{NaHCO}_{3}$ were decreased respectively to investigate the suitable values, but there is no effect on the COD removal efficiency. At the end of the experiment, the added trace nutrients and $\mathrm{NaHCO}_{3}$ were $0 \mathrm{ml} \mathrm{l}^{-1}$ and $400 \mathrm{mg} \mathrm{l}^{-1}$.

Table 1 Operational conditions of the reactor

\begin{tabular}{|c|c|c|c|c|c|c|c|}
\hline $\begin{array}{c}\text { Variable } \\
\text { Unit }\end{array}$ & $\begin{array}{l}\text { Time } \\
\text { day }\end{array}$ & 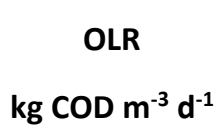 & $\begin{array}{l}\text { HRT } \\
\mathrm{h}\end{array}$ & $\begin{array}{l}\text { CODin } \\
\mathrm{mg} \mathrm{l}^{-1}\end{array}$ & pHin & $\begin{array}{c}\text { Trace } \\
\text { Nutrients } \\
\left(\mathrm{ml} \mathrm{l}^{-1}\right)\end{array}$ & $\begin{array}{l}\mathrm{NaHCO}_{3} \\
\left(\mathrm{mg} \mathrm{l}^{-1}\right)\end{array}$ \\
\hline 1 & $0-21$ & $1.0 \pm 0.1$ & 14.4 & $603 \pm 79$ & $6.60 \pm 0.50$ & 3 & \\
\hline 2 & $22-34$ & $0.9 \pm 0.1$ & 14.4 & $570 \pm 58$ & $7.24 \pm 0.20$ & 3 & 200 \\
\hline 3 & $35-42$ & $1.9 \pm 0.1$ & 14.4 & $1160 \pm 38$ & $7.80 \pm 0.23$ & 3 & 400 \\
\hline 4 & $43-47$ & $3.8 \pm 0.2$ & 14.4 & $2275 \pm 126$ & $8.45 \pm 0.65$ & 3 & 880 \\
\hline 5 & $48-72$ & $5.9 \pm 0.2$ & 14.4 & $3558 \pm 131$ & $7.99 \pm 0.30$ & 3 & 1400 \\
\hline 6 & $73-82$ & $9.8 \pm 0.6$ & 8.0 & $3261 \pm 196$ & $8.03 \pm 0.23$ & 3 & 1400 \\
\hline 7 & 83-91 & $10.4 \pm 0.6$ & 8.0 & $3468 \pm 203$ & $8.03 \pm 0.20$ & 1.5 & 1400 \\
\hline 8 & 92-99 & $10.7 \pm 01$ & 8.0 & $3581 \pm 26$ & $7.71 \pm 0.19$ & 0 & 1000 \\
\hline 9 & $100-119$ & $11.1 \pm 0.6$ & 8.0 & $3710 \pm 204$ & $7.74 \pm 0.28$ & 0 & 800 \\
\hline 10 & $120-130$ & $11.1 \pm 0.3$ & 8.0 & $3691 \pm 111$ & $7.46 \pm 0.05$ & 0 & 600 \\
\hline 11 & 131-137 & $11.2 \pm 0.4$ & 8.0 & $3723 \pm 116$ & $7.56 \pm 0.16$ & 0 & 400 \\
\hline
\end{tabular}

\subsection{Stover and Kincannon model}

Stover and Kincannon have proposed a design concept of total organic loading rate and established a kinetic model for biofilm reactor. Substrate utilization rate is only considered as a function of the organic loading rate as shown in the following equations.

$$
\frac{\mathrm{ds}}{\mathrm{dt}}=\frac{\mathrm{U}_{\max }\left(\mathrm{QS}_{0} / \mathrm{V}\right)}{\mathrm{K}_{\mathrm{B}}+\left(\mathrm{QS}_{0} / \mathrm{V}\right)}
$$




$$
\begin{aligned}
& \frac{1}{\mathrm{OLR}_{\text {removal }}}=\frac{\mathrm{K}_{\mathrm{B}}}{\mathrm{U}_{\max }} \cdot \frac{1}{\mathrm{OLR}}+\frac{1}{\mathrm{U}_{\max }} \\
& \frac{1}{\mathrm{OLR} \mathrm{R}_{\text {removal }}}=\mathrm{a} \cdot \frac{1}{\mathrm{OLR}}+\mathrm{b}
\end{aligned}
$$

\section{Results}

\subsection{Reactor performance}

Fig. 1 showed the daily changes in COD removal efficiency and effluent volatile fatty acid (VFA) condition of the UASB reactor.

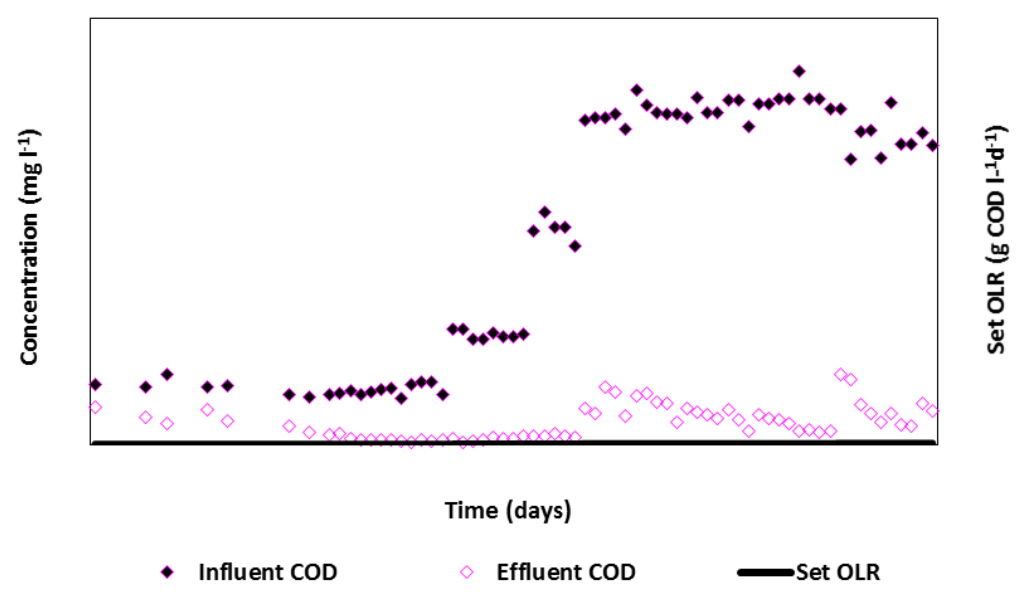

(A)

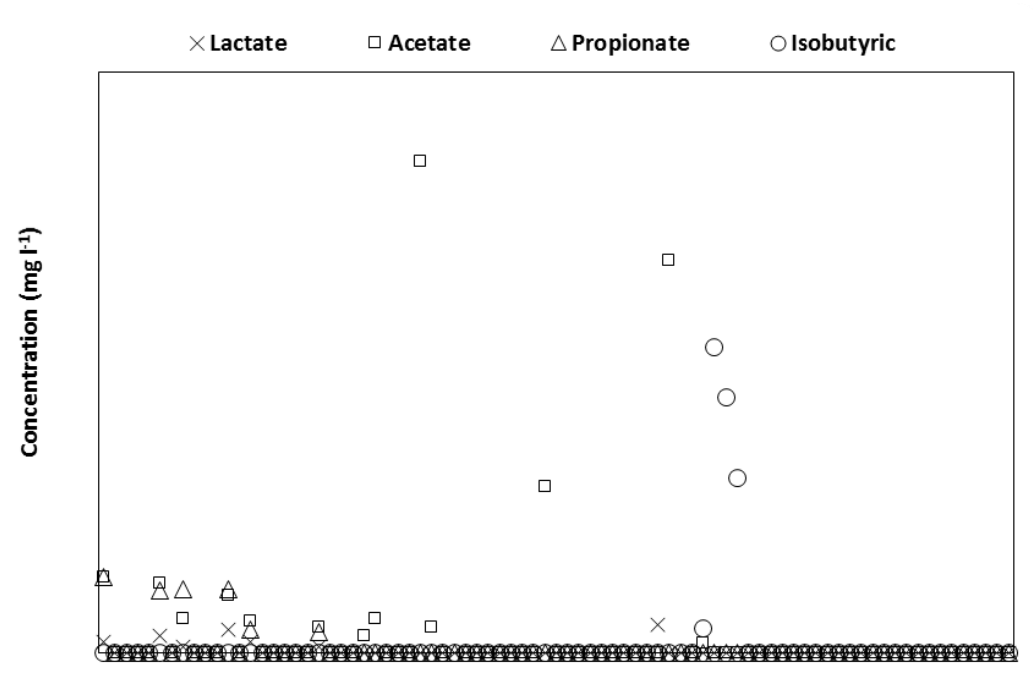

Time (days)

(B)

Figure 1. Time courses in (A) COD removal and (B) effluent VFA of the UASB reactor symbol: set OLR-set organic loading rate 
During the first 22 days of reactor operation, the COD removal efficiency was very low, but increased very fast. From day 23, the influent was completely composed of EGW, after only 3 days, the removal efficiency reached higher than $90 \%$. The influent COD level was then increased stepwise to $3,500 \mathrm{mg} \mathrm{l}^{-1}$ (OLR, $6 \mathrm{~kg} \mathrm{COD} \mathrm{m}^{-3} \mathrm{~d}^{-1}$ ) in 4 phases. A decrease in COD removal efficiency lower to $82 \%$ was found in phase 5 (influent COD, $3500 \mathrm{mg} \mathrm{l}^{-1}$ ). It took about 2 week to reach stable and higher removal efficiency during this period. Then the HRT was further shortened to $8 \mathrm{~h}$ on day 73 considering the fine treatment efficiency. This resulted in poor removal efficiency (the circle). Only one week was required to achieve one stable COD removal (about 96\%).

From phase 6 , the added trace nutrients were reduced to only half of the former value. But there is no change in $\mathrm{COD}$ removal efficiency. The input of $\mathrm{NaHCO}_{3}$ was also reduced from phase 7 step by step. At the end of this experiment, it was only $400 \mathrm{mg} \mathrm{l}^{-1}$ about alkalinity concentrations of $238 \mathrm{mg} \mathrm{l}^{-1}$ as $\mathrm{CaCO}$. This indicates that one UASB reactor based on PVA-gel beads biofilm could adapt to the change of the environment.

VFA existing in the effluent usually shows that the methane producing bacteria (MPB) cannot degrade organic acid into methane effectively. Referred to Fig. 1, the effluent VFA has clearly related to effluent COD. From day 22 to day 48 , the influent COD increased from $500 \mathrm{mg} \mathrm{l}^{-1}$ to $3500 \mathrm{mg} \mathrm{l}^{l^{-1}}$ in 4 phases. Effluent VFA was always found with lower $\mathrm{pH}$. In anaerobic processes, the balance between acid fermentation and methanogenesis is the decisive factor of successful operation. Combining with the results of COD removal, it could be concluded that the acidogenic reactions was much faster and less affected by the variations in influent flow and organic loads in this study, and the VFA degradation by the methanogenesis was the rate limiting step. Other than acetate, propionate and isobutyric out of the routine route for degradation of EG were also detected in the effluent. A hypothesis based on respiratory movement was made. Bad mix condition was often found in the UASB reactor, which leads to long-time starvation in some parts of the sludge layer. Self-degradation in these parts is possible and this could explain why propionate and isobutyric were found. Although the residual sludge from one anaerobic reactor is not so much, sludge treatment is still needed. Following the results in this experiment, artificial designation is expected for reducing residual sludge.

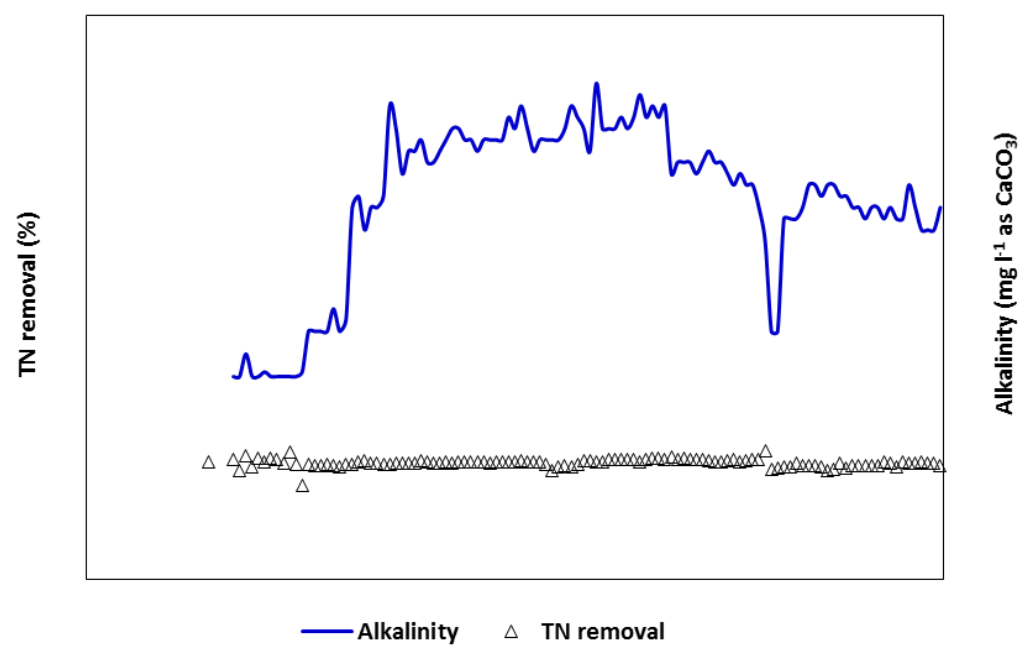

Figure 2. Daily changes in TN removal. Symbol: TN R.R.-total nitrogen removal rate

Changes in total nitrogen (TN) removal was shown in Fig. 2. The influent TN was contributed by added urine. The residual nitrogen of the effluent was in the form of ammonia nitrogen. The TN removal efficiency could reach $20 \%$ in average before day 72 . Free ammonia stripping was seemed as the main way for TN removal. On day 73, a big decrease was found, which could be explained by the consumption of $\mathrm{NaHCO} 3$ due to the accumulation of VFA in the reactor. From day 92, the added NaHCO3 was also reduced stepwise. This was reflected by the decrease in TN removal. This could be explained by decreasing 
$\mathrm{pH}$ which could affect the free ammonia generation. Without considering the effect of the added $\mathrm{NaHCO}$, there was almost no removal in TN for the UASB reactor. The calculated average CODremoved:TNremoved:TPremoved was only 3500:32:5.6 which means that lower nutrients input is feasible for EGW treatment.

\subsection{PVA-gel beads development}

At first, the PVA-gel beads were white in color. The variations in appearance were recorded using a digital camera. After cultivated by CSL, it expressed in yellowish. Following only one month of operation, some PVA gel developed black. At the end of this study, the color of PVA-gel beads turned completely to black, while there was no natural granule found in the reactor.

The matured black PVA-gel beads had an average settling velocity $322 \mathrm{~m} \mathrm{~h}^{-1}\left(9 \mathrm{~cm} \mathrm{~s}^{-1}\right)$ and $0.24 \mathrm{~g} \mathrm{VSS} \mathrm{g}^{-1}$ PVA gel. Comparing with the size 2-3mm (Zhang et al., 2009), the settling velocity improved obviously, which could explain no flush-out PVA-gel beads was found during this experiment. This demonstrated that the inert carrier for the UASB reactor should be controlled in a reasonable size.

The surface of PVA-gel beads was covered with dense sludge. A few large cavities were found following fine cavities distributed all over the surface, which is for gas production. The bacteria attached on the PVA-gel beads was composed of heterogeneous population including short and long rods, cocci and filaments. The microbial structures of the PVA-gel beads from CSL and EGW were similar in appearance (Zhang et al., 2009). But no bacteria were found in the inner part which was different with a size of 2-3 $\mathrm{mm}$. A size of 3-4 mm of PVA-gel beads might be ranged out as biocarrier other than nuclei.

Anaerobic biodegradation of organic capitalizes on a consortium of microorganisms capable of degrading the organic to methane $(\mathrm{CH} 4)$ and carbon dioxide $(\mathrm{CO} 2)$. The consortium consists of fermentation, hydrogen producing fatty acid oxidation, and methane producing organisms. The methane-producing microorganisms are also known as methanogens. Methanogens are strict anaerobes in the Archaea group. The methanogens have a high degree of substrate specificity. Among these methanogens, Methanosaeta spp. could be clearly distinguished by its long appearance.

The results observed by using SEM were compared to those obtained by the FISH assay with the purpose of identifying the microbial groups present in the PVA-gel beads (Fig. 3). In many cases, the hybridization fluorescence response was very strong, corroborating the SEM observation of large amounts of biomass attached on the PVA-gel support matrix. It is further thought that the methanogenic bacteria were present in abundance as suggested by the extended steady-state performance with consistent methane gas production. The identification of Methanosarcina spp. was confirmed by the samples taken from the UASB reactor.

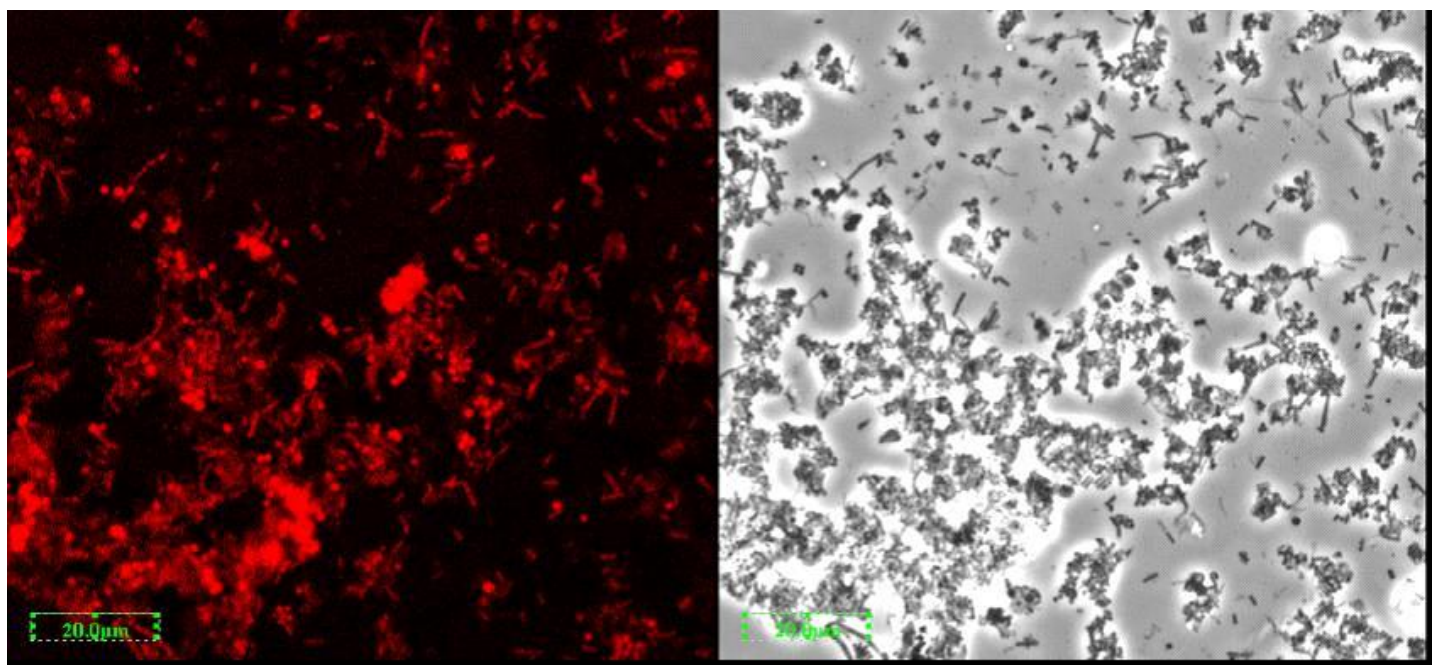

Figure 3. FISH photos of the bacteria attached on the PVA-gel beads 


\section{Discussion}

The volumetric removal efficiency is one important index to reflect the degradation ability of the bacteria in the reactor. In this experiment, volumetric removal rates turned unsteady in phase 5 and 6 . In phase 5, most of the data were below $95 \%$. This means that the degradability of the bacteria in the reactor can not meet the increase of OLR. So a relative long period was needed to cultivate more bacteria. In phase 6 , one obvious decrease in OLR removal was observed following an increase in OLR from 6 to $10 \mathrm{~kg} \mathrm{COD} \mathrm{m}^{-3} \mathrm{~d}^{-1}$. During this period, the upflow rate became fast, and the gas generation rate also increased. This could explain why the COD removal decreased. But the OLR removal soon recovered again in about one week. According the observation of the sludge layer, the PVA-gel beads began to hold the upper part of the sludge layer and a fluidized condition of PVA-gel beads was found. This indicated that the PVA-gel beads had an appropriate gravity to stay in the UASB reactor and a good ability to provide the carrier for bacteria growth.

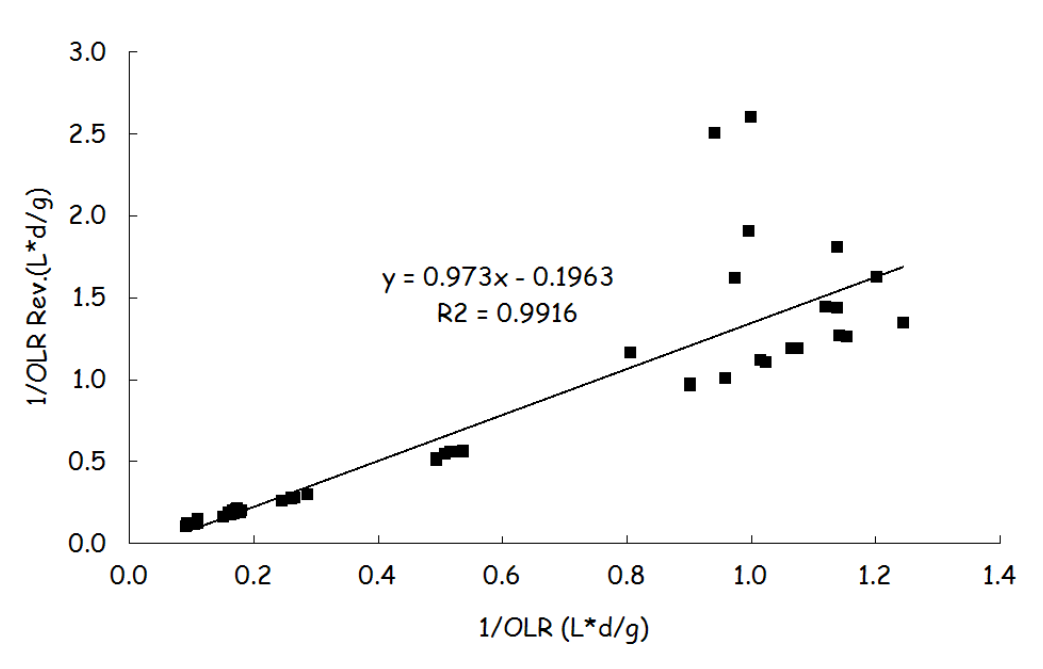

Figure 4. Stover-Kincannon model for COD removal in the UASB reactor

By the application of experimental data to the Stover-Kincannon Model, The saturation value constant (KB) and maximum spesific substrate utilization rate (Umax) were calculated as above, with values of $+\infty$. The regression line had a $\mathrm{R}^{2}$ of 0.9916 (Fig. 4).

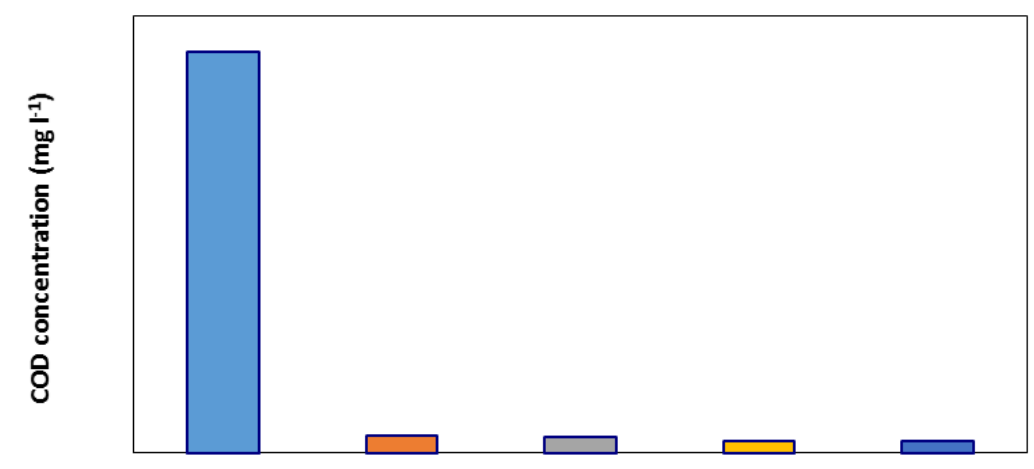

Reactor Height (cm)

Figure 5. Steady-state concentration profiles of COD following the height of the UASB reactor 
The fatal shortcoming of Stover-Kincannon Model is that there is no consideration of the biomass in the reactor, while the biomass actually decides the ability of one reactor. In this case, the biomass in the reactor is still increasing even in the end of this experiment, so the maximum OLR is hard to examine. In another word, thanks to the PVA-gel beads biocarrier, the biomass retaining ability has obviously improved.

During the experiment period, the PVA-gel beads always settled in the bottom of the UASB reactor. According to the COD concentration profiles following the height (Fig. 5), only about $60 \mathrm{mg} \mathrm{l}^{-1}$ COD was removed by the upper part of the reactor. It could be concluded that the EG was most degraded by the PVA-gel beads layer. The average biomass attached to the PVA gel was almost equal to the value of the natural granules and the color of the PVA-gel turned completely black during the study. The results showed that PVA-gel beads were helpful to retain in the reactor with high biomass attachment.

At the end of the experiment, the added trace nutrients and $\mathrm{NaHCO} 3$ were $0 \mathrm{ml} \mathrm{I}^{-1}$ and $400 \mathrm{mg} \mathrm{l}^{-1}$. This means that the biomass attached on PVA-gel beads could endure fewer nutrients and lower alkalinity. The PVA-gel biofilm in this study could function effectively in place of biocarrier to retain enough sludge in the reactor, and the reactor could run at a lower running cost.

\section{Conclusions}

The COD removal efficiency in this study could reach a high value about $95 \%$ with an OLR $11 \mathrm{~g} \mathrm{COD} \mathrm{l}^{-1} \mathrm{~d}^{-1}$ for EGW treatment. The influent COD was about $3500 \mathrm{mg} \mathrm{l}^{-1}$ almost same as the real wastewater for the following application. As the attached bacteria proceeded in the reactor with time, the color of the PVA changed obviously. The PVA-gel was black in color at last. There were no granules found in the UASB reactor. About $0.2455 \mathrm{~g} \mathrm{MLSS} \mathrm{g}^{-1}$ PVA-gel was found from the UASB reactor. The PVA gel used in this study appeared to have worked well as a biocarrier in the UASB reactor without any flotation.

\section{Acknowledgements}

This research was supported by the National Natural Science Foundation of China (51108108), Guangxi Natural Science Foundation (2014 GXNSFBA118265), Guangxi Key Laboratory of New Energy and Building Energy Saving (12J-21-2), the Project of High Level Innovation Team and Outstanding Scholar in Guangxi Colleges and Universities.

\section{References}

Amanatidou E., Samiotis G., Trikoilidou E., Pekridis G. and Taousanidis N. (2015), Evaluating sedimentation problems in activated sludge treatment plants operating at complete sludge retention time, Water Research, 69, 20-29.

APHA (1995), Standard method for the examination of water and wastewater, 19th ed. American Public Health Association, Washington, D.C.

Blika P.S., Stamatelatou K., Kornaros M. and Lyberatos G. (2009), Anaerobic digestion of olive mill wastewater, Global NEST Journal, 11, 364-372.

Dareioti M.A. and Kornaros M. (2015), Anaerobic mesophilic co-digestion of ensiled sorghum, cheese whey and liquid cow manure in a two-stage CSTR system: Effect of hydraulic retention time, Bioresource Technology, 175, 553-562.

Diamantis V. and Aivasidis A. (2010), Kinetic analysis and simulation of UASB anaerobic treatment of a synthetic fruit wastewater, Global NEST Journal, 12, 175-180.

Hassania A.H., Borgheia S.M., Samadyarb H. and Ghanbaric B. (2014), Utilization of moving bed biofilm reactor for industrial wastewater treatment containing ethylene glycol: kinetic and performance study, Environmental Technology, 35, 499-507.

Kennedy K. and Barriault M. (2005), Effect of recycle on treatment of aircraft de-icing fluid in an anaerobic baffled reactor, Water S.A., 31, 377-384.

Manser N.D., Mihelcic J.R. and Ergas S.J. (2015), Semi-continuous mesophilic anaerobic digester performance under variations in solids retention time and feeding frequency, Bioresource Technology, 190, 359-366. 
Orecki A., Tomaszewska M., Karakulski K. and Morawski A.W. (2006), Separation of ethylene glycol from model wastewater by nanofiltration, Desalination, 200, 358-360.

Vanwonterghem I., Jensen P.D., Rabaey K. and Tyson G.W. (2015), Temperature and solids retention time control microbial population dynamics and volatile fatty acid production in replicated anaerobic digesters, Scientific Reports, 5.

Vlassis T., Antonopoulou G., Stamatelatou K. and Lyberatos G. (2012), Anaerobic treatment of glycerol for methane and hydrogen production, Global NEST Journal, 14, 149-156.

Zhang W., Furukawa K. and Rouse J.D. (2007), Bench-scale study using PVA gel as a biocarrier in a UASB reactor treating corn steep liquor wastewater, Water Science and Technology, 56, 65-71.

Zhang W., Xie Q., Rouse J. D., Qiao S. and Furukawa K. (2009), Treatment of high-strength corn steep liquor using cultivated polyvinyl alcohol gel beads in an anaerobic fluidized-bed reactor, Journal of Bioscience and Bioengineering, 107, 49-53.

Zhang W., Zhang X., Wang D., Koga Y., Rouse J.D. and Furukawa K. (2011), Trace elements enhance biofilm formation in UASB reactor for solo simple molecule wastewater treatment, Bioresource Technology, 102, 9296-9299.

Zitomer D., Ferguson N., McGrady K. and Schilling J. (2001), Anaerobic co-digestion of aircraft deicing fluid and municipal wastewater sludge, Water Environment Research, 73, 645-654. 